\title{
mssaico
}

\section{Para além do}

"teto de vidro": o

trabalho feminino

e as representações

do "ideal" de

mulher executiva

\section{Silvana Rodrigues de Andrade ${ }^{1}$}

\footnotetext{
1 Programa de Pós-Graduação em História, Política e Bens Culturais da Fundação Getúlio Vargas (RJ).
}

\section{Resumo:}

Este estudo tem como objetivo refletir sobre alguns aspectos do trabalho feminino no Brasil e investigar as imagens atribuídas às mulheres em cargos de chefia nas primeiras publicações da revista Vida Executiva, de junho a dezembro de 2004, considerando a hipótese de que essas trabalhadoras fazem parte de representações recentes das mulheres no mercado de trabalho brasileiro essa análise poderá auxiliar no entendimento da construção das múltiplas identidades desse grupo.

Palavras-chave: gênero, mulheres executivas e representações, trabalho

\section{Abstract:}

This paper studies offers a reflection about labor's women market in Brazil and how these women were portrayed in the early editions of the magazine, namely between June and December, 2004. Under the hypothesis that these portraits provide a recently representation of women in the Brazil labor market, this analysis can provide a better understanding of this group's identities. 


\section{Alguns aspectos do trabalho feminino no Brasil}

A partir da década de 1930, as iniciativas do governo Vargas $^{2}$ foram determinantes para a reestruturação do mercado de trabalho no Brasil, contribuindo para a ampliação dos postos de trabalhos formais e a redução do desemprego e da informalidade. Essa trajetória se mantém progressiva até a década de 1970 (Pochmann, 2002), sendo impulsionada na década de 1940 pelo início do processo de industrialização ${ }^{3}$ e reforçada pela expansão das indústrias siderúrgica, petrolífera, química, farmacêutica e automobilística nas décadas seguintes. Entre 1940 e 1980 o emprego com registro aumentou em 6,2\% e o desemprego variou em $0,5 \%$ (Pochmann, 2002), comprovando o crescimento dos empregos formais.

A partir de 1980 o mercado de trabalho brasileiro passa a apresentar características distintas do padrão até então estabelecido após a década de 1930 . Com as mudanças ocorridas no mundo do trabalho e na economia mundial e brasileira, a partir desse período, a dinâmica de crescimento do emprego formal é interrompida e o mercado de trabalho no Brasil passa a apresentar novas características.

Em conjunto com uma inflação alta e um processo de recessão econômica a população economicamente ativa aumentou de $39,6 \%$ para $43,3 \%$, somente no período de 1979 e 1989. Esse aumento foi influenciado significativamente pela continuidade da entrada de mulheres no mercado de trabalho após 1970. Tanto que, ao final dos anos 80, mais de um terço da população economicamente ativa era composto por mulheres (Baltar e Henrique, 1994).

A participação da mulher em atividades produtivas no Brasil não é recente. Ainda na Primeira República, as mulheres, principalmente aquelas oriundas das camadas populares, já exerciam atividades produtivas. A maioria delas residia em área rural - característica predominante da população brasileira num momento anterior ao processo de urbanização e trabalhava em suas próprias casas, exercendo um importante papel no modelo de produção familiar. Apesar de sua inegável importância no processo produtivo, as mulheres eram reconhecidas apenas como as responsáveis pela manutenção do equilíbrio doméstico familiar (Weinstein, 1995; Cappellin, 2006; Soihet, 2006; Possas, 2007). Na indústria, a participação das mulheres também era significativa, sobretudo nas regiões que sofriam maior influência do processo de modernização - como São Paulo, em 1920, onde elas representavam $29 \%$ do total de trabalhadores da indústria e, especificamente, no ramo têxtil, sua atuação era superior à masculina, perfazendo $58 \%$. No Rio de Janeiro, a força de trabalho feminina representava $27 \%$ dos trabalhadores de todos os ramos industriais, $39 \%$ no ramo

\footnotetext{
2 Como exemplo dessas medidas, podemos citar a criação do Ministério do Trabalho Indústria e Comércio em 1930, a adoção da lei de sindicalização em 1931, a criação da carteira de trabalho em 1932, a Consolidação das Leis do Trabalho (CLT) em 1943 e a própria definição da lei de nacionalização do trabalho, exigindo que $2 / 3$ dos trabalhadores fossem brasileiros (Castro, 2002).

${ }^{3}$ Neste período, importantes indústrias foram criadas como a CSN (Companhia Siderúrgica Nacional) em 1941, a Fábrica Nacional em 1943 e a Companhia Hidrelétrica de São Francisco em 1945 (Castro, 2002).
} 
têxtil (Batalha, 2000:10).

A partir da década de 1970 a participação feminina no mercado de trabalho abrange diferentes camadas sociais, parte fruto das conquistas políticas dos movimentos feministas 4 na luta pelos direitos da mulher e sua autonomia na esfera pública, contribuindo significativamente para mudanças de comportamentos e valores sociais e auxiliando na construção de uma nova representação da mulher trabalhadora.

Um outro dado relevante, no impacto do crescimento dessa participação, é a própria mudança do contexto econômico a partir da década de 1980, no qual se faz necessária a contribuição financeira de outros integrantes na renda familiar devido à recessão e à perda de poder aquisitivo.

Mas essa inserção da mulher no mercado de trabalho brasileiro foi crescendo com maior relevância a partir da década de 1990, com um avanço expressivo no período compreendido entre 1993 e 2005, que contou com um aumento de 28 para 41,7 milhões de mulheres no mercado de trabalho formal (Bruschini, 2007).

Tal participação se apresenta de diferentes formas e possui significados distintos. Uma parcela significativa do trabalho feminino está associada à má qualidade de empregos, resultado não apenas da "precarização", fruto do desemprego estrutural e da flexibilização das leis que regulamentam o mercado de trabalho como um todo, mas também das diferentes condições de competição na busca por melhores postos de trabalho, o que se traduz muitas vezes em informalidade. ${ }^{5}$ Por outro lado, temos um grupo que logrou o acesso a ocupações de prestígio, conquistando posições bem remuneradas em sua trajetória profissional, como as de gerência e diretoria (Bruschini, 2007).

Segundo a análise da condição feminina no mercado de trabalho no Brasil nos anos 1990, realizada por Costa e Neves (2002), considerando dados do IBGE, algumas características já se apresentavam nesse período, como a "interferência de outros fatores não referidos à qualificação e à oferta de emprego, tais como estado conjugal, número e idade de filhos, possibilidades financeiras de terceirizar o cuidado de filhos pequenos" (op. cit, p. 126); o aumento da participação de mulheres mais velhas, casadas e mães; a maior participação feminina em cargos da administração pública e a permanência de vínculos empregatícios mais frágeis comparativamente aos dos homens.

O aumento da participação de mulheres no mercado de trabalho brasileiro, nesse período, pode ser visto como um reflexo das mudanças ocorridas no contexto econômico do país, como a abertura econômica iniciada no governo Collor (1990-1993) e intensificada no governo Itamar Franco com o Plano Real e aprofundadas nas gestões de Fernando Henrique

\footnotetext{
4 Para um melhor entendimento dos debates e construção histórica dos movimentos feministas ver Ergas (1994); Soihet (2007) e Costa (2007).

${ }^{5}$ Ver Abreu (1994); Abreu e Sorj (1993); Costa e Bruschini (1989); Lobo (1991) e Neves (1992).
} 
Cardoso (1995-2002) e, no plano internacional, com o processo de globalização (Costa e Neves, 2002).

A implementação do Plano Real em 1994 possibilitou a redução dos índices inflacionários e permitiu uma maior estabilidade financeira para o país, refletindo em um maior crescimento econômico, que atingiu o patamar de 6\% no mesmo ano. A partir de 1996 ocorre uma desaceleração, culminando em uma nova estagnação entre 1998 e 1999 e posteriormente um retorno do crescimento a partir de 2000 (Saboia, 2000). Consequentemente, toda essa flutuação da economia irá refletir diretamente na estruturação do mercado de trabalho.

A curva de crescimento dos postos de trabalho no setor terciário e nas atividades de comércio mantém-se progressiva, saindo de um patamar de $56 \%$ na segunda metade da década de 1980 para 69,4\% em 2000 (Montali, 2004).

Como consequência do aumento do processo de terceirização, ocorre um crescimento do trabalho autônomo e dos trabalhadores temporários. Essas características do mercado de trabalho no período apontam para um processo de precarização e da diminuição dos níveis de emprego no período. Em 2000 o país registrava um taxa de 17,6\% de desemprego, fruto de uma maior flexibilização das relações de trabalho. Mas em contrapartida contribuíram também para o surgimento de um número maior de pequenas e médias empresas (Cardoso; Comin; Guimarães, 2001 apud Montali, 2004), proporcionando a abertura de novas possibilidades de inserção no mercado de trabalho, mas que em contrapartida são orientadas por vínculos mais frágeis de contratação.

Essa será uma característica predominante do Brasil no período pós 2000. Os reflexos dessa tendência foram sentidos em várias cidades do país, mas principalmente nas regiões metropolitanas, que tendem a ter uma estruturação maior do mercado formal, como é o caso de São Paulo. Conforme demonstra Montali (2004):

O emprego formal regulamentado caiu de $63 \%$ em 1989, para menos de 50\% em 2000; crescem as proporções de assalariados sem registro, que passam de 9\% em 1989 para 14\% em 2000, bem como os trabalhadores autônomos que eram cerca de $16 \%$ em 1989 para cerca de 23\% em 2000, o emprego doméstico passa de $5 \%$ para $7 \%$ (p.4).

Essa nova configuração do mercado de trabalho irá impactar em novos rearranjos familiares para manutenção da renda. Em 1985, apenas 37\% das mulheres casadas contribuíam com a renda familiar, em 2000 esse número era de 52,2\% (Montali, 2004).

Esses dados refletem um maior partilhamento dos integrantes da família nas responsabilidades de manutenção do grupo familiar, inclusive considerando o aumento da contribuição dos jovens. Essas análises são pertinentes para modelos tradicionais de organizações familiares, mas sabemos que hoje o crescimento de mulheres exercendo o 
papel de "chefe de família" é significativo e novas formas de reorganizações familiares são registradas.

Essas mudanças e novas configurações não refletem apenas os impactos da economia na vida das pessoas, considerando que essas dimensões não estão desarticuladas, demonstram também algumas alterações simbólicas importantes na reconstrução do ideário da atuação feminina na sociedade, visando atuações sociais mais amplas que permitam a conciliação de vida familiar com a participação na esfera pública, em especial no espaço produtivo. $^{6}$

Parte desse crescimento e inserção ainda está associada ao incremento da escolaridade da população feminina. Segundo dados do último censo do IBGE (2006), as mulheres já possuem um nível de escolaridade maior do que os homens. Aquelas que não possuem ocupação formal no mercado de trabalho possuem, em média, 7 anos de estudo, enquanto os homens têm em média 6,7 anos. Quando analisamos a população que detém uma ocupação formal no mercado de trabalho, esse número é ainda mais expressivo: as mulheres apresentam em média 8,2 anos de estudo e os homens, 7,2, o que significa 1 ano a mais de formação. Essa estatística já credencia o Brasil para alcançar a Meta do Milênio, ${ }^{7}$ referente à promoção da igualdade entre os sexos e à autonomia das mulheres.

Tal vantagem educacional não se traduz, no entanto, em maior remuneração. Segundo resultados do mesmo censo, o rendimento médio das mulheres, em 2006, representava cerca de $65,6 \%$ do rendimento dos homens. Esse fenômeno não é uma característica associada apenas ao caso brasileiro. Apesar de apresentarem lacunas menores, os países com um índice maior de desenvolvimento econômico e democrático também vivenciam diferenças significativas na comparação da remuneração entre trabalhadores do sexo masculino e trabalhadoras do sexo feminino. Na França, por exemplo, essa diferença é de cerca de $8 \%$ em cargos não executivos e de $28 \%$ em cargos executivos (Ferrand, 2007).

Além das diferenças de renda, uma outra questão que aumenta a complexidade da atuação das mulheres no mercado de trabalho é a conciliação trabalho-família, intensificada pela desigualdade da divisão do trabalho doméstico e pela maternidade. Dificuldade presente também em outros países, como Portugal (Guerreiro, Abrantes e Perreira, 2004) e França (Ferrand, 2007).

No Brasil, a regulamentação do trabalho feminino teve o seu início no período de

\footnotetext{
${ }^{6}$ Informações mais detalhadas desse processo de mudança podem ser visualizadas no survey elaborado por Paola Cappellin (2005).

7 As Metas do Milênio constituem uma relação de 8 metas voltadas para o desenvolvimento sócioambiental, com as quais se comprometeram os 191 países que compõem a ONU, em setembro de 2000, com o compromisso de atingi-las até 2015. As demais metas consistem em erradicar a extrema pobreza e a fome, atingir o ensino básico universal, reduzir a mortalidade infantil, melhorar a saúde materna, combater o HIV/Aids, a malária e outras doenças, garantir a sustentabilidade ambiental e estabelecer uma parceria mundial para o desenvolvimento (ONU, 2007).
} 
1932 a 1934, na gestão do então Ministro Salgado Filho, com a criação de numerosas leis trabalhistas. Melhorias significativas ocorreram com a criação do Ministério da Previdência e Assistência Social, durante o governo de Ernesto Geisel (1974-1979), com a adoção de outras tantas que abarcavam não apenas os direitos dos trabalhadores como também os de suas famílias, aumentando a rede de proteção social para aqueles inseridos no mercado formal, como a instituição da licença maternidade (Gomes, 2002).

Essa lei permitiu às mulheres que ocupavam uma posição no mercado formal de trabalho, ausentar-se por determinado período ${ }^{8}$ de suas atividades produtivas para se dedicarem aos cuidados com o filho, sem prejuízo direto de remuneração. Esse direito, reconhecido há décadas pela Organização Internacional do Trabalho, muitas vezes ainda representa no Brasil um entrave para a inserção da mulher no mercado formal de trabalho, como no caso das denúncias ocorridas em 1994, de "que empresários brasileiros estariam exigindo de mulheres que buscavam se empregar, um atestado de laqueadura, isto é, uma comprovação médica de que não poderiam ter mais filhos" (Gomes, 2002:09).

Em 1999, houve uma revisão do artigo 392 da CLT (Consolidação das Leis dos Trabalhos) que trata da proteção do trabalho da mulher ${ }^{9}$, tendo sido definida a obrigatoriedade da oferta de creche ou reembolso-creche para todas as empresas que possuam mais de 30 mulheres trabalhando (art. 388 a 390). Apesar da obrigatoriedade já existir há mais de 7 anos, em 2007, em média, apenas 43\% das empresas pesquisadas pela Price Waterhouse Coppers ${ }^{10}$ ofereciam esse benefício no Brasil.

A falta de cumprimento da legislação trabalhista não é uma exclusividade nossa. Outros países também vivenciam essa realidade, como Portugal, por exemplo. Segundo Guerreiro, Abrantes e Perreira (2004), as empresas portuguesas tampouco cumprem integralmente a legislação do trabalho em vigor no país e não possuem políticas internas que promovam uma melhor integração trabalho-família, o que acarreta maiores dificuldades para a manutenção da mulher no mercado de trabalho em empresas privadas.

No caso brasileiro, as irregularidades no cumprimento da legislação trabalhista de proteção à mulher e a ausência de iniciativas empresariais que contribuam com a conciliação trabalho-família não impediu o crescimento da inserção feminina no mercado de trabalho e a conquista de cargos executivos.

\footnotetext{
8 Inicialmente o período de licença-maternidade no Brasil era de 30 dias, atualmente na legislação em vigor é de 120 dias. No dia 09/09/2008 o presidente Luís Inácio Lula da Silva sancionou a lei n⿳o 11.770 que amplia esse período para 180 dias. Com essa lei, de forma não obrigatória, as empresas poderão adotar essa política para as suas funcionárias e obter desconto integral no Imposto de Renda do valor de pagamento de salário adicional aos 60 dias a mais de licença. A lei foi sancionada em 2008, mas para atender as necessidades de estudos de renúncia fiscal pelo Estado, tem previsão de entrar em vigor a partir de 2010 (SENADO FEDERAL:2007).

9 Um debate importante sobre a importância da rede de proteção social na inserção da mulher no espaço público encontra-se em Costa (1999).

10 Pesquisa realizada com 92 empresas de pequeno, médio e grande porte no Brasil.
} 
O crescimento da participação de mulheres em cargos de chefia, nos últimos anos ${ }^{11}$, aparece como um dado relevante e abre novas perspectivas de estudo sobre o tema, comprovando a heterogeneidade da atuação feminina no mercado de trabalho brasileiro. Estudos realizados por Bruschini (2007), identificam que:

Para o ano de $2000,24 \%$ dos 42.276 cargos de diretoria computados pela RAIS $^{12}$ eram ocupados por mulheres, dado surpreendente, face ao conhecimento disponível, nos estudos sobre o trabalho feminino, sobre a dificuldade de acesso das trabalhadoras a cargos de chefia. As informações obtidas para 2004 revelam que, nessa data, cerca de 31\% dos 19.167 cargos de diretores gerais de empresas do setor formal eram ocupados por mulheres (op. cit. pág. 17).

O percentual de $31 \%$ de mulheres ocupando cargos de diretoria torna-se significativo, considerando que o grupo de cargos executivos no Brasil não engloba apenas diretores, mas também gerentes de empresas e que tradicionalmente esses cargos são ocupados por homens.

Em suma, o crescimento da inserção de mulheres no mercado de trabalho a partir da década de 1970 e o aumento do registro de ascensão para cargos executivos nas décadas seguintes tornam-se ainda mais surpreendente por ocorrer em um período que apresenta fases de desaceleração econômica e de significativas mudanças no mundo do trabalho.

Esse fato reforça a influência da autonomia dos agentes sociais em estabelecer estratégias e encontrar "brechas" diante das dificuldades de determinados contextos. A atuação de indivíduos e grupos sofrerá os reflexos oriundos das estruturas sociais que se encontram inseridos, em contrapartida, tais estruturas são influenciadas pelas ações desses agentes. Essa articulação é dinâmica, estabelecendo um processo contínuo de diálogo entre os agentes e as estruturas. As diferentes "leituras" e apropriações realizadas pelos agentes sociais tendem a exercer um efeito performativo nas estruturas, contribuindo para as suas constantes modificações.

No caso específico dos estudos de gênero esse fato, ainda sinaliza a importância de refutarmos as perspectivas reificadas pela "vitimização" e "heroicização", riscos frequentes no tratamento de estudos de grupos considerados "minoritários" e com dificuldades de inserção na esfera pública.

A própria separação entre privado e político e as análises baseadas na dicotomia subordinação versus dominação devem ser evitadas para que possamos produzir reflexões

\footnotetext{
11 Ver Bruschini e Puppin (2004).

12 A Relação Anual de Informações Sociais - RAIS - é uma base de dados do Ministério do Trabalho e Emprego - MTE, que fornece, anualmente, dados sobre o número de empregos e sobre algumas de suas características nas empresas do setor formal (Bruschini e Puppin, 2004).
} 
que possam nos auxiliar em um melhor entendimento das relações de poder existentes na interseção do campo de trabalho e gênero.

\section{As representações do "ideal" de mulher executiva}

Com esse contexto favorável de aumento da participação mulheres no mercado de trabalho, em junho de 2004 foi lançada no Brasil, pela editora Símbolo, a revista Vida Executiva, abordando questões, símbolos e significados atribuídos ao grupo de mulheres que ocupa posição de chefia.

A editora Símbolo, em 2004, já se firmava como uma editora de publicações de revistas direcionadas a um público feminino mais amplo, como as revistas Uma, Corpo a Corpo, Dieta já, Vida Saúde e Meu Nenê, voltadas para saúde, beleza e maternidade.

A redação e o corpo editorial da revista Vida Executiva eram compostos majoritariamente por mulheres, que ocupavam os cargos de editora-chefe, repórter, diretora de divisão, revisora e editora de arte. Ao todo eram oito profissionais do sexo feminino e apenas um homem participando da produção gráfica, ou seja, mulheres escrevendo e editando para mulheres. Esta equipe se manteve durante as sete edições e contou com a participação de outras pessoas como colaboradores. Neste grupo havia mais equidade, inclusive abrangendo, ao longo do período, um maior número de homens, em média 14 para 13 mulheres.

A partir da análise das sete primeiras publicações da Revista, de junho a dezembro de 2004, este estudo busca refletir sobre "os dispositivos materiais e formais" (Chartier, 1989) da revista, como capa, contracapa, títulos, disposição e estrutura das seções. São informações importantes para entendermos melhor o "sentido das formas" (Idem) com que essas trabalhadoras foram apresentadas nessa primeira fase da revista.

A escolha por iniciar este estudo a partir de tais suportes materiais, antes mesmo de analisarmos com profundidade o conteúdo textual presente nas narrativas dos artigos, visa à interpretação dos símbolos e dos significados atribuídos por uma revista ao "ideal" de mulher executiva.

Serão estas informações iniciais que irão marcar a "identidade" da revista nas bancas e auxiliar na captação da atenção dos leitores. As informações presentes nessas seções funcionarão como um "convite" para o leitor (neste caso, provavelmente para as leitoras), influenciando na sua escolha em meio às disputas dos inúmeros títulos disponibilizados em um mercado editorial cada vez mais efervescente.

As capas - No período de publicação das sete edições da revista Vida Executiva, as capas foram destinadas às pioneiras. Cada edição deu exclusividade e destaque a uma única 
pioneira que havia conseguido romper o "teto de vidro", ${ }^{13}$ possivelmente sinalizando a abertura de espaço para as seguintes. É importante ressaltar o slogan que permaneceu ao longo das sete primeiras edições - "a revista da mulher de sucesso" - o que reforça esta hipótese.

Da primeira a sétima edição aparecem algumas mulheres que ocupavam em 2004 um cargo de grande prestígio em empresas privadas de diferentes segmentos, como de presidente ou de diretoria, além de algumas empresárias. É importante diferenciar essas duas categorias: executivas ${ }^{14}$ e empresárias. Apesar de ambas partilharem alguns significados atribuídos ao "mundo" empresarial, são categorias diferentes, considerando que as empresárias por serem donas do próprio negócio possuem um outro tipo de inserção, atuação e outras relações de poder em um campo com disputas diferentes. Enquanto a empresária busca a inserção e o bom posicionamento do seu negócio no mercado, a mulher executiva encontra-se como empregada de uma empresa em um cargo de prestígio e vivenciará disputas no campo por esses postos.

As relações de poder, disputas e tensões são diferentes, considerando que a relação de trabalho das mulheres executivas será regida por um contrato, entre empregado e empregador, ou seja, uma relação mediada pelas leis trabalhistas vigentes no país. É importante sinalizar as diferenças dessas categorias e reforçar que o foco da análise proposta será pautada na categoria "executivas".

Para elaborar essa análise partimos da hipótese de que as executivas fazem parte de representações recentes da mulher no mercado de trabalho e possuem um espaço significativo na esfera pública, em especial nas empresas e em algumas mídias impressa e eletrônica.

É importante ressaltar que esse espaço nos meios de comunicação é muito diferente do anteriormente ocupado pela mulher na imprensa na passagem para século $X X$, no qual as lutas pela emancipação feminina eram apresentadas com descrédito (Soihet, 2004). Na revista Vida Executiva essas trabalhadoras ocupam um espaço de destaque, geralmente valorizando a conquista e a atuação em cargos tradicionalmente ocupados por homens, muitas vezes em representações e narrativas próximas de "heroínas".

Mas como essas mulheres são apresentadas nas capas da revista? Como a primeira edição foi destinada a uma empresária (Cristiana Arcangeli), começamos a análise a partir da edição de julho, na qual aparece a executiva Eneida Bini anunciando o seu novo cargo de diretora na Herbalife ${ }^{15}$ depois de 23 anos na Avon ${ }^{16}$.

\footnotetext{
13 "Diz respeito àqueles postos-chave na hierarquia superior das empresas e instituições, considerados como ainda não ultrapassáveis e inatingíveis pelas mulheres [...] termo cunhado pelo Wall Street Journal em 1985" (Rocha, 2006: 102).

14 Sobre a construção da categoria "executivos" na França, ver Boltanski (1982).

15 Empresa americana de comercialização de produtos de redução de peso e nutrição.
} 
Ela ressalta: "nem sempre o cargo de mais glamour é o que oferece melhores oportunidades" Essa frase sinaliza uma justificativa para a sua escolha, comparando a Avon, uma empresa ligada à beleza e com uma maior projeção no mercado empresarial, com a Herbalife que é uma empresa de menor porte.

A terceira edição foi destinada a executiva Amália Sina ${ }^{17}$ :

"Presidente da Walita ${ }^{18}$ aos 40 anos, fez crescer as vendas em mais de $16 \%$ desde 2002: falamos hoje com uma mulher de verdade". O trocadilho do nome "Amália" com "Amélia, a mulher de verdade" ${ }^{19}$, refuta a imagem da mulher que se dedica apenas às tarefas domésticas e não se encontra inserida em atividades produtivas. Nega também uma postura mais submissa da mulher e valoriza os significados atribuídos à carreira profissional executiva na busca de maiores resultados de vendas para as empresas.

A edição de setembro foi destinada a Cheiko Aoki, filha de imigrantes japoneses de São Paulo: "uma das maiores executivas de hotelaria, a presidente da Rede Blue Tree ${ }^{20}$ é uma verdadeira encantadora de hóspedes". Como Cheiko também é dona de sua própria empresa, ou seja, uma empresária; não realizamos uma análise mais detalhada deste exemplar.

$\mathrm{Na}$ quinta edição (outubro) aparece Rose Koraicho, "presidente da Koema Empreendimentos Imobiliários, um imenso império moldado em sonhos e concretos":

A carreira de Rose Koraicho também se encontra na interseção entre executiva e empresária, já que o seu pai é dono da Koema Empreendimentos Imobiliários e Rose uma de

${ }_{16}$ Empresa de produtos de beleza, fundada nos Estados Unidos. A sua segunda maior unidade no mundo encontra-se no Brasil.

17 Nota dos editores: a troca de formato após a publicação do artigo impossibilitou a reprodução das imagens desse artigo.

${ }_{18}$ Empresa voltada para produção de eletrodomésticos, fundada no Brasil em 1930. Atualmente é uma das empresas do grupo Philips.

19 Alusão a uma marchinha clássica do carnaval brasileiro, composta por Mário Lago e Ataulfo Alves em 1941, na qual descrevem a saudade que tinham de uma mulher chamada "Amélia". Segundo a música, "Amélia não tinha a menor vaidade, Amélia é que era a mulher de verdade" (Correio Braziliense, 2009). Até hoje, no Brasil, o termo "Amélia" é usado para representar a mulher que não trabalha fora de casa e "apenas" destina o seu tempo para cuidar do lar e da família.

${ }^{20}$ Empresa do ramo de hotelaria. 
suas herdeiras. Este fato sinaliza também as diferentes possibilidades de acúmulo de capitais para inserção e ascensão no campo.

O destaque da edição de novembro é a executiva Maria Sílvia Bastos:

"A dama de aço que teve coragem de trocar o cargo de presidente da CSN $^{21}$ por qualidade de vida." Como a CSN é uma empresa de produção de aço e Maria Sílvia Bastos possui a fama no mercado de trabalho de ser uma executiva mais rigorosa, a revista faz uma associação a Margareth Thatcher (a dama de ferro).

A executiva teve uma projeção maior no mercado após assumir a presidência da principal siderúrgica do país, antes ocupava o cargo de secretária de fazenda na gestão de César Maia na prefeitura do Rio de Janeiro, em 1995. Neste momento da publicação da matéria na Revista Vida Executiva, ela informava a sua decisão de sair da presidência da CSN para abrir a sua própria consultoria e virar uma empresária. Em 2006 ela retorna para o mercado de trabalho e assumi a presidência da seguradora Icatu Hartford, voltando para a posição de executiva, cargo que mantém atualmente (Revista Bovespa e Isto é, 2009).

Maria Sílvia Bastos é uma executiva muito conhecida e reconhecida no meio empresarial e constantemente é citada como uma pioneira na ascensão para um cargo executivo de nível hierárquico superior, como de presidência.

A última edição do ano também foi destinada a uma empresária, Cristina Carvalho Pinto, e por este motivo também não realizamos uma análise deste exemplar.

Percebe-se que há uma diversidade nessas apresentações, trabalhadoras atuando em diferentes segmentos da economia, com inserções e trajetórias distintas no campo, mas também algumas semelhanças: mulheres de cor de pele clara, com uma grande projeção no campo, aparentando cerca de 40 anos, bem vestidas e maquiadas, sempre com um estilo clássico e sofisticado de vestuário, na maioria um terninho que acompanha a cor de fundo do título da revista e joias. Na primeira página da revista pode-se ter acesso às informações das origens das roupas, normalmente de lojas de grifes internacionais consideradas de um mercado de luxo, como Empório Armani, Chanel, Dolce \& Gabbana e Daslu, além de joias da H. Stern e algumas do próprio acervo pessoal das executivas.

Segundo Bourdieu (2007), grupos considerados "dominantes" se afirmam em três formas principais de consumo para se distinguir dos demais grupos: "alimentação, cultura e despesas com apresentação de si e com representação (vestuário, cuidados de beleza, artigos de higiene e pessoal de serviço)" (op. cit, p. 174), portanto esses ícones de consumo

${ }^{21}$ Empresa de produção de aço, fundada em 1941 no Brasil. 
de um mercado de luxo não representam apenas o universo econômico de um grupo de mulheres que a partir do seu trabalho possui um poder aquisitivo maior, mas contemplam também uma dimensão simbólica importante na formação de uma identidade de grupo e na sua distinção frente aos demais.

Em relação às chamadas das capas dessas primeiras publicações, a maioria enfatiza uma postura e um comportamento de protagonista das mulheres na construção de suas carreiras, principalmente nas chamadas principais em destaque durante esse primeiro ano (2004), como "compartilhar é crescer" (julho), "promova-se!" (agosto), "arrisque mais, tome a iniciativa" (outubro) e "talento todo mundo tem" (novembro)

Além das formas de apresentação de si presentes nas capas das revistas, podemos avaliar esses símbolos e significados em outros dois espaços do periódico: na contracapa destinada ao anúncio publicitário e na própria estrutura das seções.

A estrutura das seções - Em relação a esta última, temos a seguinte disposição:

A primeira seção é intitulada "na capa", com informações de algumas chamadas apresentadas na capa da edição.

Em seguida, a seção "informação", que traz dicas de comportamentos mais aceitáveis no ambiente empresarial, com uma subseção intitulada "etiqueta básica", que irá discorrer sobre como agir em várias situações do cotidiano de trabalho. Alguns exemplos são: um almoço de negócios; reuniões de trabalho; como usar corretamente o celular; como se deve proceder, ao sair de férias, com os pertences pessoais que estão na mesa de trabalho; como se vestir se tiver que trabalhar no final de semana, entre outros.

A seção está organizada no estilo de perguntas e respostas para situações corriqueiras do ambiente de trabalho.

As duas subseções seguintes apresentam dicas para auxiliar na ascensão da carreira. Com os subtítulos "evolução" e "tendência", apresentam recomendações de atitudes e comportamentos necessários para um melhor posicionamento no "campo" (Bourdieu, 1989), entre eles, o desenvolvimento de competências como criatividade, iniciativa e inovação, além da importância de compartilhar conhecimentos e delegar atividades, administrar o tempo e a forma correta de fazer apresentações de trabalho, entre outros.

As subseções "hi tech" e "tecnologia", abordam as tendências de novas tecnologias em informática e telefonia celular. Por último, temos a subseção intitulada "contexto", que trata de questões políticas da atualidade, como na edição de outubro de 2004, em que faz uma breve análise das eleições americanas com os perfis das candidaturas de George W. Bush e John Kerry. 
A seção "personalidades" é destinada à executiva retratada na capa e narra a sua trajetória e experiência no ambiente empresarial, além de trazer uma entrevista com um consultor de recursos humanos do mercado ou psicoterapeuta que apresenta, mais uma vez, algumas dicas do melhores comportamentos para se inserir, consolidar e permanecer no campo.

"Imagem em alta" é uma seção dedicada às tendências da moda - vestuário, maquiagem, perfumes, cosméticos e cortes de cabelos direcionados a um público mais clássico e sofisticado - contemplando algumas poucas páginas para dicas de nutrição e cuidados com a saúde. Similar aos modelos já existentes de revistas destinadas ao público feminino.

A penúltima seção, intitulada "relacionamento", expõe questões em sua maioria voltadas para a conciliação família-trabalho e as relações com colegas e chefe. Um exemplo é o artigo da edição de novembro de 2004, que aborda os dilemas da maternidade e os cuidados com os filhos, com o título "a hora de ter filhos - é preciso considerar as necessidades do casal e o momento profissional". Seguindo esta mesma tendência, a edição de julho de 2004 apresenta o artigo "socorro! crianças em casa", recomendando roteiros de atividades para o período de férias dos filhos.

Por fim, ao final da revista, de forma destacada em um quadro, mas em letra menor, temos as "seções básicas", com carta e e-mails de leitoras, dicas de investimentos financeiros, endereços dos produtos listados e informações sobre o que fazer no tempo livre e também uma seção de astrologia voltada para a carreira profissional.

Esta estrutura das seções permaneceu a mesma no decorrer das sete primeiras edições da revista. A diversidade dos temas enfocados encontra convergência na representação de uma categoria similar a um guia de auto-ajuda, possivelmente no intuito de auxiliar novatas e aspirantes na criação de um habitus ${ }^{22}$ (Bourdieu, 1989) e fazendo alusão a um "processo civilizador" (Elias, 1994), o que contribuirá na formação de estratégias de inserção e de manutenção em um campo que possui regras e costumes próprios.

As contracapas - Durante as sete primeiras edições, as contracapas trouxeram propagandas com variedade de produtos, como novos modelos de celulares (junho), travesseiros mais confortáveis (julho e agosto), tintas para o cabelo (outubro) e bolsas sofisticadas (dezembro). Um dado importante que nos chamou a atenção em duas propagandas de contracapa foi a afirmação do poder da mulher sendo usada como uma estratégia de marketing em detrimento da diminuição do poder e da "utilidade" dos homens na vida dessas mulheres.

Como exemplo, vê-se a propaganda de um seguro de automóvel, que inclui serviços

22 Segundo Bourdieu (1989), habitus corresponde às atitudes, formas de pensar adquiridas e interiorizadas por um indivíduo durante o seu processo de socialização. 
de pequenos reparos e consertos em residência, com o slogan: "seu marido acaba de perder uma utilidade" (novembro).

$\mathrm{Na}$ edição de setembro, a contracapa é destinada à propaganda de um seguro de vida direcionado às mulheres, com cobertura extensiva para câncer de mama. É apresentado o slogan publicitário: "se as mulheres já eram seguras de si, agora então nem se fala", escrito à mão em um guardanapo com um beijo de batom, e que tem ao seu lado uma bolsa e um brinco expostos em uma mesa, caracterizando que foi escrito por uma mulher.

Em uma outra propaganda de carro, no verso da capa da edição de outubro do mesmo ano, está a descrição da chamada: "controle $C D$ player no volante de carro. Os homens estão cada vez com menos utilidade", reafirmando tal característica.

A partir desta análise inicial da revista, percebe-se que os ícones de consumo, as propagandas publicitárias e as principais chamadas da revista convergem para a afirmação do poder dessa nova mulher trabalhadora.

Ainda nestas primeiras edições, as imagens das pioneiras demonstrando a "quebra do teto de vidro" são frequentemente utilizadas como estratégia para construção de um "ideal" de mulher trabalhadora, possivelmente sinalizando para as aspirantes as possibilidades de ascensão.

Ainda podemos identificar a diversidade de símbolos, formas e sentidos atribuídos à nova mulher trabalhadora, em especial àquelas que ocupam cargos executivos.

Esses elementos atribuídos a esse grupo podem auxiliar na formação de um "ethos", de uma "visão de mundo" (Geertz, 1989) e principalmente de um habitus (Bourdieu, 1989), que contribuem para aumentar as possibilidades de inserção, distinção e ascensão em um campo com frequentes disputas.

Essa reflexão inicial ainda demonstra a imagem de uma mulher com poder em relação às demais e principalmente frente aos homens, considerando que o poder não é dado, mas exercido (Foucault, 2006), um dos espaços escolhidos por essas mulheres para esse exercício será o trabalho em cargos executivos. 
Esse espaço confere a essas trabalhadoras um maior prestígio e uma das formas de reforçar essa posição no campo é através da elegância e sofisticação nas formas de apresentação de si.

Outra característica importante é afirmação da autonomia dessas trabalhadoras na construção de suas trajetórias pessoal e profissional a partir das imagens apresentadas na Revista e principalmente nas chamadas de capa.

Outras reflexões a respeito dos demais elementos presentes nas capas, análise das edições seguintes e das narrativas das matérias poderão nos permitir um melhor entendimento da construção deste "ideal" de mulher executiva.

Assim como, estudos complementares com entrevistas contemplando não apenas a trajetória profissional dessas trabalhadoras, mas também as suas histórias de vida, tornam-se relevantes para entendermos as "apropriações" (Chartier, 1989) que essas mulheres fazem de tais leituras e símbolos e, principalmente, as ressignificações e os sentidos que atribuem a essas representações em suas práticas.

\section{Bibliografia:}

ABREU, Alice. "Especialização flexível e gênero - debates atuais". São Paulo em Perspectiva, vol. 8, n.1, São Paulo, Fundação SEADE, 1994.

; SORJ, Bila. O trabalho invisível - estudos sobre trabalhadores a domicílio no

Brasil. Rio de Janeiro, Rio Fundo Editora, 1993.

AVON. Disponível em http://www.br.avon.com/PRSuite/home/home.jsp acesso em 20/01/2009.

BALTAR, Eduardo de Andrade e HENRIQUE, Wilmês. Emprego e renda na crise contemporânea do Brasil. IN. O mundo do trabalho, crise e mudança no final do século. São Paulo, Edit. Página Aberta, 1994.

BATALHA, Cláudio. O movimento operário na Primeira República. Rio de Janeiro, Jorge Zahar Editor, 2000.

BLUE HOTELS. Hisponível em http://www.bluetree.com.br/home/home.asp?secao=home acesso em 20/01/2009.

BOLTANSKI, Luc. “Les cadres. La formation d'un groupe social.” Paris, Minuit, 1982.

BOURDIEU, Pierre. "A distinção - crítica social do julgamento". São Paulo: EDUSP, Porto 
Alegre, RS: Zouk, 2007.

. “O poder simbólico." Rio de Janeiro, Difel/ Bertrand Brasil, 1989.

BRUSCHINI, Cristina e PUPPIN, Andréa Brandão. "Trabalho de mulheres executivas no Brasil no final do século XX". Cadernos de Pesquisas da Fundação Carlos Chagas. v.34, n. 121, janabr 2004, pp. 105 a 138.

BRUSCHINI, Cristina "Trabalho e gênero no Brasil nos últimos 10 anos". In: Seminário Internacional Mercado de Trabalho e Gênero: Comparações Brasil-França. Rio de Janeiro, UFRJ/IFCS, 09 a 12 de Abril de 2007. Disponível em http://www.fcc.org.br/mulher. Acesso em $10 / 07 / 07$.

CAPPELLIN, Paola. "Mulheres pobres e violência no Brasil urbano". In: PRIORE, Mary del (org.). História das mulheres no Brasil. São Paulo, Contexto, 2006.

trabalho no Brasil. Editora FGV, 2005.

In: ARAÚJO, Clara e SCALON, Celi (orgs). Gênero, família e

CHARTIER, Roger. "Le monde comme representation." Annales ESC, novembre-decembre 1989 , n.6, p. 1505-1520.

COSTA, A. de Oliveira e BRUSCHINI, Cristina (orgs.). Rebeldia e submissão: estudos sobre a condição feminina. São Paulo, Vértice/ Fundação Carlos Chagas, 1989.

CORREIO BRAZILIENSE. "Mário Lago, cantor e compositor." Brasília, sexta-feira, 31 de maio de $2002 . \quad$ Disponível em http://www2.correioweb.com.br/cw/EDICAO 20020531/pri cul 310502.htm acesso em 29/01/2009.

COSTA, Delaine Martins e NEVES, Maria da Graça Ribeiro (orgs.). "A condição feminina nos países do Mercosul. Sistema integrado de indicadores de gênero nas áreas de trabalho e educação." Rio de Janeiro, IBAM, 2002.

COSTA, Suely Gomes. "Proteção social, maternidade transferida e lutas pela saúde reprodutiva." Revista Estudos Feministas. V.7, n.12, Florianópolis, 1999.

"A voz das mulheres: linhas da vida e associativismos feministas. Rio de Janeiro, anos 80 e 80 do século XX": Ed. Civilização Brasileira, 2007. In: Cultura política e leituras do passado: historiografia e ensino de história. Rio de Janeiro: Ed. Civilização Brasileira, 2007.

CSN. Companhia Siderúrgica Nacional. Disponível em http://www.csn.com.br/portal/page? pageid=456,170749\& dad=portal\& schema=PORTAL acesso em 20/01/2009. 
ELIAS, Nobert. "O processo civilizador: uma história dos costumes." Rio de Janeiro, Edit. Zahar, vol.1, 1994.

ERGAS, Yasmine. "O sujeito mulher." O feminismo dos anos 1960-1980. In: DUBY, G. e PERROT, M. História das mulheres no ocidente. O século XX. Porto: afrontamento, São Paulo: EBRADIL, 1994, v.5, p. 583-611.

FERRAND, Michele. "Les dilemmes dês femmes diplômées, ici et ailleurs". In: Seminário Internacional Mercado de Trabalho e Gênero: Comparações Brasil-França. Rio de Janeiro, UFRJ/ IFCS, 09 a 12 de Abril de 2007. Disponível em http://www.fcc.org.br/mulher acesso em 10/11/08.

FOUCAULT, Michel. "Estratégia, poder e saber." Coleção ditos e escritos, v.4, Edit. Forense Universitária, Rio de Janeiro, 2006.

GOMES, Ângela de Castro. A invenção do trabalhismo. 1 ed. Rio de Janeiro, IUPERJ/Vértice, 1988.

Editor, 2002.

Cidadania e direitos do trabalho. Rio de Janeiro, Jorge Zahar

GOFFMAN, Erving. A representação do eu na vida cotidiana. Petrópolis, Vozes, 1989.

GUERREIRO, Maria das Dores, ABRANTES, Pedro e PEREIRA, Inês. "Relação trabalho - família em contextos organizacionais em mudança”. Disponível http://www.aps.pt/vcongresso/ateliers-pdfs.htm. 2004.

GEERTZ, Clifford. “A interpretação das culturas.” Rio de Janeiro, Editora LTC, 1989.

HERBALIFE. Disponível em http://www.herbalifeww.com/br/, acesso em 20/01/2009.

IBGE - INSTITUTO BRASILEIRO DE GEOGRAFIA E ESTATÍSTICA. Pesquisa nacional por amostra de domicílios. Diretoria de Pesquisas, Coordenação de População e Indicadores Sociais, 2006. Disponível em http://www.ibge.gov.br/home/estatistica/populacao/trabalhoerendimento/pnad2006/come ntarios2006.pdf. Acesso em 14/09/2007.

LOBO, Elizabeth. A classe operária tem dois sexos: trabalho, dominação e resistência. São Paulo, Editora Brasiliense, 1991.

NEVES, Magda de Almeida. "Mulher e trabalho: o que mudou nesta relação?" In: Anais do Encontro de Estudos Populacionais, vol. 7, 1992, Brasília.

MONTALI, Lília. Rearranjos familiares de inserção, precarização do trabalho e empobrecimento. In: XIV Encontro Nacional de Estudos Populacionais (ABEP 2004), Caxambu, 
Minas Gerais, 20 a 24 de setembro de 2004. Disponível em http://www.abep.nepo.unicamp.br/docs/rev inf/vol21 n2 2004/vol21 n2 2004 4artigo p 195a216.pdf acesso em 20/01/2009.

ONU - ORGANIZAÇÕES DAS NAÇÕES UNIDAS. Metas do milênio. Disponível em http://millenniumindicators.un.org/unsd/mispa/mi_series_results.aspx?rowld=589. Acesso em Acesso em 19-07-2007, às 17:34.

POCHMANN. Marcio. “O trabalho no fogo cruzado." São Paulo, Contexto, 2002.

POSSAS, Lídia Maria Vianna. “O projeto civilizador nas frentes pioneiras paulistas: as relações de gênero no âmbito do público/privado". In: XXIV Simpósio Nacional de História (ANPUH 2007), São Leopoldo, Rio Grande de Sul, 15 a 20 de julho de 2007.

PRICE WATERHOUSE COOPERS. Pesquisa anual de salários e benefícios. Publicação própria. Abril de 2006.

REVISTA BOVESPA. "Mulheres em ação". São Paulo, julho/setembro de 2006. Disponível em http://www.bovespa.com.br/InstSites/RevistaBovespa/99/Mulheres.shtml acesso em 27/01/2009.

REVISTA ISTO É DINHEIRO. "Maria Sílvia do aço ao seguro". São Paulo, 01 de novembro de $2006 . \quad$ Disponível em http://www.terra.com.br/istoedinheiro/476/financas/maria silvia do aco ao seguro.htm acesso em 27/01/2009.

REVISTA VIDA EXECUTIVA. Ano 1, N. 1 a 7. São Paulo, Editora Símbolo, jun-dez de 2004.

ROCHA, Cristina Tavares da Costa Rocha. "Gênero em ação? Rompendo o 'teto de vidro'? Novos contextos da tecnociência." Santa Catarina, 2006, Tese de doutorado, UFSC. Disponível em http://www.cfh.ufsc.br/ dich/tese cristinadarocha.pdf. Acesso em 20/07/2007.

SENADO FEDERAL. Projeto de Lei n. 281/2005 - disponível em http://www.senado.gov.br/sf/atividade/Materia/getHTML.asp?t=6716 acesso em 18/10/2007.

SABOIA, João. "Um novo índice para o mercado de trabalho urbano no Brasil". Revista de Economia Contemporânea, v. 4, n.1, janeiro/junho de 2000.

SOIHET, Rachel. "Pisando no 'sexo frágil'” In: Nossa História. Ano 1, n. 3, janeiro de 2004. p. 14-20.

"Mulheres pobres e violência no Brasil urbano". In: PRIORE, Mary del (org.). História das mulheres no Brasil. São Paulo, Contexto, 2006 - "Femininos e cultura política: uma questão no Rio de Janeiro dos anos 1970/1980." In: Cultura política e leituras do passado: historiografia e ensino de história. Rio 
112 Para além do "teto de vidro":

o trabalho feminino e as representações do "ideal" de mulher executiva

de Janeiro: Ed. Civilização Brasileira, 2007, p. 411-436.

WALITA. Disponível em http://www.philipsbrasil.com.br/a acesso em 20/01/2009.

WEINSTEIN, Bárbara. "As mulheres trabalhadoras em São Paulo". Cadernos Pagu, vol. 4, Núcleo de Estudos de Gênero/ Unicamp, 1995. 